\title{
Strategi Akselerasi Kenaikan Pangkat dan Jabatan Dosen FKIP Universitas Mataram
}

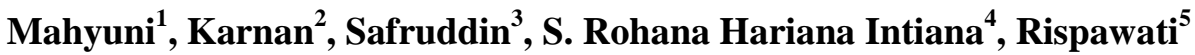 \\ ${ }^{1,4}$ Jurusan Pendidikan Bahasan dan Seni, FKIP Universitas Mataram, Mataram, Indonesia \\ ${ }^{2}$ Jurusan Pendidikan Matematika dan IPA, FKIP Univerisitas Mataram, Mataram, Indonesia \\ ${ }^{3}$ Jurusan Ilmu Pendidikan, FKIP Universitas Mataram, Mataram, Indonesia \\ ${ }^{5}$ Jurusan Ilmu Pendidikan Sosial, FKIP Universitas Mataram, Mataram, Indonesia
}

DOI: https://doi.org/10.29303/jpmsi.v2i1.22

Citation: Mahyuni. Karnan. Safruddin. Intiana, S. R. H., Rispawati. 2020. Strategi Akselerasi Kenaikan Pangkat dan Jabatan Dosen FKIP Universitas Mataram. Jurnal Pengabdian Masyarakat Sains Indonesia (JPMSI). 2(1): 52 56.

\author{
Article history \\ Received: November $20^{\text {th }} 2019$ \\ Revised: December $22^{\text {th }} 2019$ \\ Accepted: December $31^{\text {th }} 2019$ \\ *Corresponding Author: \\ Karnan, FKIP Universitas \\ Mataram, Mataram, Indonesia; \\ Email: \\ karnan.ikan@unram.ac.id
}

\begin{abstract}
Abstrak: Pada umumnya, kenaikan pangkat dan jabatan dosen seringkali terlambat. Secara umum keterlambatan itu disebabkan oleh dua hal pokok yaitu faktor diri dosen tersebut dan faktor sistem administrasi yang kurang mendukung. Padahal pangkat dan jabatan seorang dosen akan berpengaruh pada kualitas pembelajaran di perguruan tinggi, bahkan akan berpengaruh pada akreditasi program studi. Untuk itu, perlu ada strategi dan upaya dalam rangka akselerasi kenaikan pangkat dan jabatan dosen. Dalam rangka kelancaran pelaksanaan proses pengembangan karier kepada tenaga akademik/dosen di lingkungan FKIP Universitas Mataram, maka dipandang perlu dilakukannya workshop untuk menetapkan strategi akselerasi kenaikan pangkat dan Jabatan Dosen di FKIP Universitas Mataram. Untuk mempermudah dan memperlancar usulan ini, FKIP Universitas Mataram akan mengimplementasikan beberapa langkah strategis, yaitu: pembentukan tim percepatan untuk publikasi, peningkatan kapasitas sumber daya manusia, sistem arsip secara daring (online), hibah penelitian bagi dosen yang potensial naik ke jenjang Guru Besar, dan pembagian beban tugas (load) staf administrasi yang menangani urusan kenaikan pangkat dan jabatan dosen ke staf administrasi jurusan/program studi.
\end{abstract}

Kata kunci: akselerasi kenaikan pangkat, jabatan dosen, tenaga akademik

\section{Pendahuluan}

Salah satu komponen utama di setiap perguruan tinggi adalah dosen. Dosen memiliki peran yang sangat vital dalam melaksanakan fungsi perguruan tinggi terutama dalam mengembangkan dan menerapkan ilmu pengetahuan, teknologi dan seni. Menurut Undang-Undang Republik Indonesia Nomor 14 Tahun 2005 Tentang Guru dan Dosen, dosen adalah pendidik profesional dan ilmuwan dengan tugas utama mentransformasikan, mengembangkan, dan menyebarluaskan ilmu pengetahuan, teknologi, dan seni melalui pendidikan, penelitian, dan pengabdian kepada masyarakat.

Sebagai Pegawai Negeri Sipil, dosen memiliki kesempatan yang luas untuk mengembangkan karirnya. Jenjang karir dosen ini telah diatur dalam Keputusan Menteri Negara Koodinator Bidang Pengawasan Pembangunan dan Pendayagunaan Aparatur Negara Nomor 38/KEP/MK.WASPAN/1999 tentang Jabatan Fungsional Dosen dan Angka Kreditnya dan Keputusan Bersama Menteri Pendidikan dan Kebudayaan dan Kepala Badan Kepegawaian Negara Nomor 61409/MPK/KP/99 dan Nomor 181 Tahun 1999 tentang Petunjuk Pelaksanaan Jabatan Fungsional Dosen dan Angka Kreditnya. Jenjang dosen ada empat, yaitu Asisten Ahli, Lektor, Lektor Kepala, dan Guru Besar.

Berdasarkan panduan di atas, maka jenjang karir pokok dosen terletak pada jabatan akademik dosen yang disebutkan. Jenjang karir dosen tidak sama dengan tenaga penunjang (pegawai administrasi) yang mendapatkan kenaikan pangkat secara periodik setiap empat tahun. Untuk dapat 
Mahyuni et al, Jurnal Pengabdian Masyarakat Sains Indonesia 2020, 2 (1):52-56 DOI : https://doi.org/10.29303/ipmsi.v2i1.22

mencapai suatu tingkatan dalam jenjang karir tertentu, seorang dosen harus mengumpulkan point yang meliputi pendidikan dan pengajaran, penelitian, pengabdian pada masyarakat, dan tambahan.

Jika dilihat dari usianya, FKIP Universitas Mataram yang didirikan pada tahun 1981 seharusnya telah memiliki banyak dosen yang memiliki jabatan guru besar. Apalagi lebih dari $36 \%$ dosennya bergelar doktor (Tabel 1). Fakta menunjukkan bahwa karir sebagian besar dosen di FKIP Universitas Mataram tidak sesuai dengan masa kerja dan tingkat pendidikannya. Kondisi ini jauh lebih rendah jika dibandingkan dengan jumlah guru besar yang dimiliki Universias Pendidikan Ganesha (Undiksa) di Denpasar yang pendiriannya hampir sama dengan FKIP Universitas Mataram. Undiksa yang sebelumnya tergabung dalam Universitas Udayana, bernana FKIP Udayana, saat ini telah memiliki 42 orang dosen dengan jabatan Guru Besar.

\begin{tabular}{lccc}
$\begin{array}{l}\text { Tabel 1. Jabatan Fungsional Dosen FKIP } \\
\text { Universitas Mataram berdasarakan } \\
\text { Jenjang Pendidikannya Tahun 2019*) }\end{array}$ \\
\hline \multicolumn{4}{c}{$\begin{array}{c}\text { Jenjang } \\
\text { Pendidikan }\end{array}$} \\
$\begin{array}{l}\text { Jabatan } \\
\text { Fungsional }\end{array}$ & S2 & S3 & Jumlah \\
& - & 7 & 7 \\
\hline Guru Besar & 40 & 25 & 65 \\
Lektor Kepala & 27 & 29 & 56 \\
$\begin{array}{l}\text { Lektor } \\
\text { Asisten Ahli }\end{array}$ & 41 & 12 & 53 \\
$\begin{array}{l}\text { Belum memiliki } \\
\text { jabatan }\end{array}$ & 17 & - & 17 \\
Fungsional & & & \\
Jumlah & 125 & 73 & 198 \\
\hline
\end{tabular}

*) Data Sub Bagian Kepegawaian FKIP Universitas Mataram Tahun 2019.

Pada umumnya, kenaikan pangkat dan jabatan dosen lambat. Padahal pangkat dan jabatan seorang dosen akan berpengaruh pada kualitas pembelajaran di perguruan tinggi, bahkan akan berpengaruh pada akreditasi program studi. Untuk itu, perlu ada strategi dan upaya khusus untuk mendorong kenaikan pangkat dan jabatan dosen.

Dalam rangka kelancaran pelaksanaan proses pengembangan karier kepada tenaga akademik/dosen di lingkungan FKIP Universitas
e-ISSN : $2715-2537$

p-ISSN : 2715-2545

Mataram, maka dipandang perlu untuk dilakukan workshop mengenai strategi akselerasi kenaikan pangkat dan Jabatan Dosen di FKIP Universitas Mataram.

Selama ini, pola yang ada di FKIP Universitas Mataram mengikuti pola lama yaitu setiap dosen mengumpulkan sendiri bahan-bahan atau materi yang akan diusulkan dalam kenaikan pangkat mereka. Tidak bisa dipungkiri bahwa tidak semua dosen tertib dalam menata dokumen atau mengelola dokumen yang diperlukan sebagai bahan usulan kenaikan pangkatnya. Solusi yang ditawarkan untuk mengatasi persoalan yang dikemukakan di atas adalah adanya suatu mekanisme yang tegas yang dituangkan dalam bentuk Prosedur Operasinal Baku (POB) tentang proses pengurusan kenaikan pangkat dan jabatan dosen di FKIP Universitas Mataram.

Upaya perbaikan administratif yang dapat ditawarkan adalah ada pegawai administrasi khusus yang bertugas membantu pengurusan penyiapan berbagai perangkat administrasi kenaikan pangkat dan jabatan, ada tim angka kredit di setiap fakultas sebagai "konsultan", dan ada koordinasi antara pimpinan (jurusan dan fakultas) dan dosen. Target luaran yang diharapkan dari kegiatan ini adalah dihasilkannya artikel tentang mekanisme percepatan atau akselerasi pengusulan kenaikan pangkat dan jabatan dosen yang dapat digunakan tidak hanya di lingkungan FKIP Universitas Mataram, tetapi juga instansi lain yang memerlukannya.

\section{Metode}

Kegiatan pengabdian ini dilaksanakan pada tanggal 15 Nopember 2019. Pelaksanaan kegiatan dilaksanakan di Ruang Sidang FKIP Universitas Mataram. Pelaksanaan kegiatan ini menggunakan metode "workshop" yang melibatkan berbagai unsur pemangku kepentingan di FKIP Universitas Mataram, yaitu Dekanat, Senat Fakultas, KetuaKetua Jurusan dan Program Studi, dan unsur kepegawaian.

Kegiatan diawali dengan pengantar dan sambutan oleh Ketua Senat FKIP Universitas Mataram sekaligus sebagai Ketua Tim. Setelah itu, kegiatan dilanjutkan dengan sambutan Dekan FKIP Universitas Mataram yang diikuti penjelasan teknis tentang berbagai strategi yang akan ditempuh oleh FKIP Universitas Mataram terkait akselerasi 
Mahyuni et al, Jurnal Pengabdian Masyarakat Sains Indonesia 2020, 2 (1):52-56 DOI : https://doi.org/10.29303/ipmsi.v2i1.22

kenaikan pangkat dan jabatan dosen oleh Wakil Dekan bidang akademik.

Selanjutnya, diskusi dilakukan untuk menyusun mekanisme pengusulan kenaikan pangkat dan jabatan akademik dosen. Rumusan hasil diskusi akan dijadikan bahan untuk menyusun rekomendasi tentang mekanisme akselerasi kenaikan pangkat dan jabatan di FKIP Universitas Mataram.

\section{Hasil dan Pembahasan}

Berbagai permasalahan dan alternatif solusi terkait kenaikan pangkat dan jabatan dosen di FKIP Universitas Mataram muncul pada saat kegiatan workshop dilakukan. Mekanisme pengusulan kenaikan pangkat dan jabatan dosen yang diterapkan saat ini cenderung memerlukan waktu yang lama. Hal ini disebabkan oleh mekanisme (proses) dan keterbatasan sumber daya manusia yang tersedia.

Saat ini, proses pengusulan pangkat/jabatan dosen masih dilakukan dengan mekanisme menyiapkan (proses) yang memerlukan waktu lama. Seorang dosen harus mengumpulkan dan menyiapkan sendiri dokumen yang diperlukan sebagai bahan usulan kenaikan pangkatnya. Ketika merasa angkat kreditnya sudah cukup, dosen tersebut menyerahkan dokumennya kepada staf administrasi kepegawaian fakultas. Di sini, berkas usulan tadi dikelompokkan sesuai dengan ketentuan yang berlaku, yaitu: unsur utama yang terdiri dari pendidikan dan pelaksanaan tri dharma perguruan tinggi, dan unsur penunjang. Setelah dihitung dan ditabulasi, maka berkas usulan tadi dikirim ke tim Penilai Angka Kredit (PAK) dosen yang ada di jurusan masing-masing.

Hasil penilaian tim PAK jurusan ini selanjutnya dikembalikan ke bagian administrasi kepegawaian fakultas untuk diinput kembali sesuai hasil penilaian yang dilakukan. Data hasil penilaian yang sudah diinput ini berikutnya dibawa ke sidang senat fakultas untuk diverifikasi. Jika sidang senat merekomendasikan untuk diteruskan, maka selanjutnya dokumen dikembalikan ke bagian administrasi kepegawaian untuk diperbaiki jika ada kekeliruan dan diteruskan ke bagian kepegawaian universitas.

Pemeriksaan dan penilaian berkas selanjutnya diteruskan oleh bagian kepegawaian universitas ke tim pemeriksa tingkat universitas. Jika telah dinilai cukup dan memenuhi persyaratan
e-ISSN : 2715-2537

p-ISSN : 2715-2545

maka proses selanjutnya akan diteruskan ke Senat Universitas untuk mendapatkan pertimbangan dan rekomendasi senat universitas sebelum dikirim ke Kementerian Pendidikan dan Kebudayaan (sebelumnya Kementerian Riset, Teknologi dan Pendidikan Tinggi) di Jakarta. Tetapi jika menurut penilaian di tingkat universitas masih terdapat kekurangan, maka berkas usulan akan dikembalikan ke fakultas (dosen pengusul) untuk dilengkapi.

Proses di atas tentu sangat rumit dan biasanya memerlukan waktu yang tidak sedikit. Pengalaman menunjukkan bahwa satu usulan dapat memakan waktu sampai berbulan-bulan.

\section{Sumber daya manusia}

Kegiatan menyusun dan menghitung angka kredit bukanlah suatu pekerjaan yang mudah. Kegiatan ini memerlukan pengetahuan dan keterampilan tertentu. Sementara, saat ini hanya terdapat 1 (satu) orang saja staf administrasi kepegawaian FKIP Universitas Mataram yang memiliki kemampuan dan keterampilan menyusun dan menghitung angka kredit dosen.Kondisi ini dipastikan sebagai suatu permasalahan tersendiri dalam proses kenaikan pangkat dan jabatan dosen. Apalagi dalam proses pengelolaannya masih bersifat manual.

\section{Strategi akselerasi kenaikan pangkat dosen}

Mekanisme proses kenaikan pangkat dan jabatan di FKIP Universitas Mataram harus yang ada saat ini harus dikondisikan agar tidak terkesan rumit. Dalam diskusi yang dilakukan pada saat workshop dilaksanakan, beberapa langkah antisipasi yang ditawarkan dan siap untuk diimplementasikan. Beberapa langkah strategis yang akan dilakukan meliputi: pembentukan tim percepatan untuk publikasi, peningkatan kapasitas sumber daya manusia, sistem arsip secara daring (online), hibah penelitian bagi dosen yang potensial naik ke jenjang Guru Besar, dan pembagian beban tugas (load) staf administrasi yang menangani urusan kenaikan pangkat dan golongan ke staf administrasi jurusan/program studi.

Lambatnya kenaikan pangkat seorang dosen dapat terjadi karena kendala yang dihadapi terkait dengan publikasi. Untuk mengatasi permasalahan ini di FKIP akan dibentuk tim percepataan publikasi. Sebagaimana diketahui bahwa untuk jurnal terinndeks, artikel harus memenuhi ketentuan 
Mahyuni et al, Jurnal Pengabdian Masyarakat Sains Indonesia 2020, 2 (1):52-56 DOI : https://doi.org/10.29303/ipmsi.v2i1.22

yanga telah ditetapkan, baik dari segi format, substansi, maupun bahasa. Salah satu bentuk kerja dari tim ini adalah membantu para dosen yang memiliki kesulitan dalam mempublikasi artikelnya pada jurnal yang terindneks tersebut. Untuk meningkatkan kualitas pelayanan, lembaga FKIP Universitas Mataram juga akan terus meningkatkan kapasitas pegawai/staf administrasi, termasuk bidang kepegawaian. Dengan semakin banyaknya staf administrasi yang menguasai sistem administrasi di bidang ini, maka beban administrasi tentang kepangkatan ini tidak terkonsentrasi pada satu orang staf saja, melainkan terdistribusi kepada staf/pegawai lainnya.

Terkait dengan pengarsipan dokumen, tidak semua dosen melakukannya dengan baik. Akibatnya, walaupun dari jumlah poin usulan mungkin saja sudah mencukupi, namun karena sistem pengarisipannya yang tidak baik, maka proses pengusulan pangkat dan jabatan menjadi tertunda. Kondisi seperti ini sangat umum dijumpai pada banyak kalangan dosen. Kemajuan teknologi informasi yang ada saat ini memberikan kemudahan terhadap berbagai aktivitas pelayanan, termasuk dalam hal pengarsipan dokumen. Kemajuan teknologi ini telah mulai dimanfaatkan di FKIP Unram. Beberapa dokumen penting yang dibutuhkan oleh dosen terkait dengan usulan pangkat dan jabatan, misalnya surat keputusan (SK) melaksanakan Tri Dharma Perguruan Tinggi tidak perlu lagi menambah kesibukan dosen karena semuanya tersedia secara daring (dalam jaringan). Hal ini tentu sangat membantu dalam proses melengkapi berkas usulan kenaikan pangkat dan jabatan dosen.

Selain itu, dalam mendapatkan dana riset yang berasal dari sumber-sumber yang kompetitif, tidak semua dosen bisa memperolehnya. Karena itu, fakultas juga memberikan fasilitas khusus kepada dosen FKIP Universias Mataram yang berupa hibah penelitian kepada dosen yang potensial untuk mencapai jabatan Guru Besar. Hibah penelitian ini dimaksudkan agar artikel yang dihasilkan dapat menghasilkan artikel yang dimuat di jurnal nasional bahkan internasional terindeks yang bereputasi. Dengan demikian, persyaratan yang terkait dengan poin ini dapat didapatkan solusinya.

Hal lain yang akan dilakukan oleh lembaga FKIP Univeresitas Mataram untuk mendukung program akselerasi kenaikan pangkat dan jabatan
e-ISSN : 2715-2537

p-ISSN : 2715-2545

dosen ini adalah dengan membagi beban tugas (load) staf administrasi yang selama ini terkonsentrasi pada satu orang, pada saat yang akan datang akan didistribusikan ke jurusan/program studi. Dalam hal ini, Ketua Jurusan/Program Studi akan dibantu oleh tenaga admin yang ada di jurusan/program studi. Hal ini sesuai dengan mekannisme yang dituangkan dalam PERMENPANRB No. 17/2013 jo No. 46/2013 IX Pasal 15-22 yang secara singkat disajikan dalam Gambar 1.

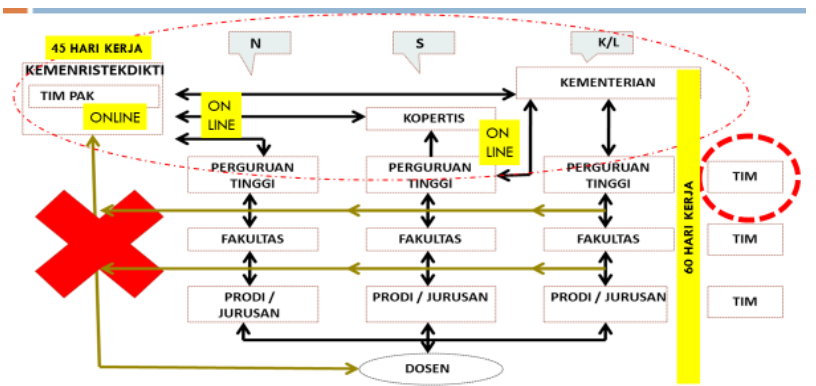

Gambar 1. Alur Proses Usulaan Kenaikan Pangkat dan Jabatan Dosen

Berdasarkan Gambar 1, dosen pengusul menyerahkan berkas usulan mereka ke Jurusan/Program Studi. Di sini terlihat bahwa proses pemeriksaan dan penilaian berkas usulan sepenuhnya di Jurusan/Program Studi. Selain itu, proses pemeriksaan dokumen di tingkat fakultas tidak diperlukan lagi. Pemeriksaan dokumen langsung dilanjutkan ke Universitas. Penilian angka kredit dari tingkat universitas ke kementnerian dilakukan secara daring (online). Berdasarkan skema ini, waktu yang dibutuhkan untuk pemeriksaan dan penilaian angka kredit maksimal 45 hari kerja. Dengan demikian, kebijakan yang diambil oleh FKIP Universitas Mataram yang sekaligus sebagai rekomendasi dari workshop ini merupakan langkah yang tepat.

\section{Kesimpulan}

Proses usulan kenaikan pangkat dan jabatan dosen di FKIP Universitas Mataram harus dikondisikan agar prosesnya tidak terkesan rumit. Untuk mempermudah dan memperlancar usulan ini, FKIP Universitas Mataram telah melakukan beberapa langkah strategis, yaitu: pembentukan tim percepatan untuk publikasi, peningkatan kapasitas sumber daya manusia, sistem arsip secara daring (online), hibah penelitian bagi dosen yang potensial naik ke jenjang Guru Besar, dan pembagian beban tugas (load) staf administrasi yang menangani 
urusan kenaikan pangkat dan jabatan dosen ke staf administrasi jurusan/program studi.

\section{Saran}

Untuk memastikan implementasi dari apa yang telah ditetapkan di atas, maka semua unsur yang ada di fakultas harus mendukung kebijakan yang siap diimplementasikan ini.

\section{Ucapan Terima Kasih}

Terima kasih kami ucapkan kepada Universitas Mataram yang telah memberikan dana untuk kegiatan ini melalui sumber dana DIPA BLU (PNBP) Universitas Mataram. terima kasih juga kepada Dekanat, Senat Fakultas, Ketua-Ketua Jurusan dan Program Studi beserta unsur kepegawaian atas segala bantuan dan partisipasi sehingga kegiatan pengabdian ini terlaksana dengan baik dan lancar.

\section{Daftar Pustaka}

Keputusan Menteri Negara Koodinator Bidang

Pengawasan Pembangunan dan

Pendayagunaan Aparatur Negara Nomor 38/KEP/MK.WASPAN/1999 tentang Jabatan Fungsional Dosen dan Angka Kreditnya.

Keputusan Bersama Menteri Pendidikan dan Kebudayaan dan Kepala Badan Kepegawaian Negara Nomor 61409/MPK/KP/99 dan Nomor 181 Tahun 1999 tentang Petunjuk Pelaksanaan Jabatan Fungsional Dosen.

Undang-Undang Republik Indonesia Nomor 14 Tahun 2005 Tentang Guru dan Dosen.

PERMENPANRB No. 17 tahun 2013. 